\title{
Discussões do Conselho Deliberativo da Reserva Extrativista de Canavieiras, Bahia, Brasil: da gestão pesqueira à ambiental *
}

\section{Discussion of the Board of the Extractive Reserve of Canavieiras, Babia, Brazil: fisheries management to environmental management}

\author{
Leriane Silva Cardozo ${ }^{\circledR,}, 1$, Micheline Flôres Porto ${ }^{1}$, Patrícia Carla Barbosa Pimentel ${ }^{1}$, \\ Jaqueline Sicupira Rodrigues ${ }^{1}$, Alexandre Schiavetti ${ }^{1,2}$, Sofia Campiolo ${ }^{1,3}$
}

\section{RESUMO}

Este trabalho teve por objetivo identificar e analisar as discussóes ocorridas no âmbito do conselho deliberativo da Reserva Extrativista de Canavieiras, que influenciaram e/ou influenciam as decisóes relativas às atividades de pesca, num processo de tomada de decisáo participativa. A Reserva Extrativista de Canavieiras (Decreto s/nº em 05/06/06) está localizada ao sul do Estado da Bahia, Brasil, e possui conselho deliberativo instituído que visa regular processos, mecanismos e organizaçóes através dos quais os atores da sociedade exercem suas funçóes, reforçando o Princípio da Participaçáo Popular, exigível principalmente quando se trata de Unidade de Conservação de Uso Sustentável. Nesse sentido, a identificação e análise das discussôes do conselho deliberativo, prioritariamente, em relação às atividades de pesca, gestão ambiental e aos princípios da boa governança, possibilitaram compreender as relaçóes de responsabilidade e responsabilização, aspectos vinculados a governança ambiental em áreas protegidas. Em relaçáo aos procedimentos metodológicos, este estudo estruturou-se com base na pesquisa qualitativa, com coleta de informaçóes de dados secundários a partir de documentos institucionais e legislaçóes específicas. Foram analisadas dezenove atas, de 2009 a 2012 . Verificou-se a identificação, discussão e sugestão aos problemas relativos à pesca, de forma direta ou indireta e até mesmo dos instrumentos de gestão, entretanto, em registros das atas, não ficou evidenciado o cumprimento ou a adoção de tais açóes e medidas estabelecidas. Os principais temas discutidos no período, foram: conselho deliberativo, licenciamento ambiental, autorizaçóes diretas, contrato de concessão do Direito Real de Uso e plano de manejo. Em relação aos princípios da boa governança, constatou-se a predominância dos princípios da Legitimidade e Voz e de Direção em relação aos princípios da Execução, da Responsabilidade e da Justiça.

Palavras-chave: Reserva Extrativista, Conservação, Governança.

\footnotetext{
@ - Corresponding author.
}

1 - Universidade Estadual de Santa Cruz (UESC), Pós Graduação em Desenvolvimento e Meio Ambiente (PRODEMA), Campus Soane Nazaré Andrade, Rodovia Jorge Amado, Km 16, Sobradinho, Ilhéus-BA, Brasil. CEP: 45.662-900. emails: Cardozo lerianecardozo@gmail.com, Porto michelinefloresporto@gmail.com,Pimentel patriciacbp@yahoo.com.br,Rodrigues jaquelinesicupira@gmail.com

2 - Departamento de Ciências Agrárias e Ambientais, UESC.e-mail:aleschi@uesc.br

3 - Departamento de Ciências Biológicas, UESC. e-mail: sofia.campiolo@gmail.com 


\section{ABSTRACT}

This study had as its objective to identify and analyze the discussions that occurred under the deliberative council of Extractive reserve of Canavieiras which influenced andlor influence the decisions regarding the fishing activities, in a process of participatory decision making. The Extractive Reserve of Canavieiras (Decree s/no 06/05/06) is located in the south of the State of Bahia, Brazil, and has deliberative council established to regulate processes, mechanisms and organizations by means of which the actors of the society exercise their functions, by reinforcing the Principle of Popular Participation, due mainly when it comes to the Conservation Unit for Sustainable Use. In this sense, the identification and analysis of the discussion of the deliberative council, in order of priority, in relation to fishing activities and environmental management as well as the principles of good governance, enabled the understanding of the relationship of responsibility and accountability, aspects linked to environmental governance in protected areas. In relation to methodological procedures, this study is structured on the basis of qualitative research, with the gathering of information of secondary data from institutional documents and specific legislation. From 2009 to 2012, nineteen records were analyzed. It was checked the identification, discussion and suggestion to issues related to fisheries, either directly or indirectly, and including management tools, however, in records it was not evidenced the compliance or the adoption of such actions and established measures. The major topics discussed, at the time, were; deliberative council, environmental licensing, direct authorizations, concession of the Real Right to Use the Management Plan. In relation to the principles of good governance, it was observed the predominance of the principles of Legitimacy and Voice and of Direction in relation to the principles of Execution, of Responsibility and of Justice.

Keywords: Extractive Reserve; Conservation; Governance.

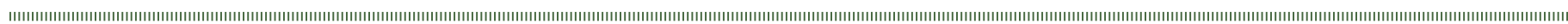

\section{INTRODUÇÁO}

No Brasil, as reservas extrativistas (Resex) são uma categoria de unidade de conservaçáo (UC) de uso sustentável instituída pelo Sistema Nacional de Unidades de Conservação (SNUC) que tem como objetivos a proteção dos meios de vida, a cultura das populaçóes residentes e uso sustentável dos recursos naturais da unidade, definidos por Lei $n^{\circ}$ 9.985/2000 (DOU, 2000a). Conceitualmente, as áreas protegidas (AP) abarcam as UC (Schenini et al., 2004; Perreira \& Scardua, 2008), divididas no SNUC em duas tipologias com características distintas: a) Unidades de Proteção Integral- visa a preservação da natureza, admitindo o uso indireto dos seus recursos naturais, e b) Unidades de Uso Sustentável - admite o uso direto de uma parcela de seus recursos naturais, compatibilizando a conservaçáo da natureza com o uso sustentável (Schenini et al., 2004; Medeiros, 2006).

Acerca das Resex, estão baseadas no extrativismo, agricultura de subsistência e criação de animais de pequeno porte, e possuem como princípio básico de funcionamento a participação popular, principalmente das populaçóes que tradicionalmente já utilizavam os recursos ambientais para sobrevivência (Antunes, 2010). Na zona costeira e litorânea, as Resex objetivam a conservação do meio ambiente marinho e a extração dos seus recursos de forma sustentável pelas comunidades tradicionais, visando à subsistência destas, e vêm se destacando como importante iniciativa política por atender as necessidades dos pescadores costeiros de pequena escala (Silva, 2007) e, juntamente com as demais UC marinhas, podem contribuir para o aumento da densidade de estoques pesqueiros, sobretudo, por meio de um manejo sustentável e aumento de fiscalizaçáo (Floeter et al., 2007).

A criação da Resex pelo poder público é precedida de uma mobilização social - de sua população tradicional ou representação - em busca por soluçóes aos problemas socioambientais (Fadigas \& Garcia, 2010), em especial, conflitos fundiários (Medeiros, 2006), e visa regularizar o território mediante exploração de seus recursos de modo sustentável.
No intuito de assegurar o funcionamento e envolvimento popular, as Resex são administradas por órgão gestor, o Instituto Chico Mendes de Conservaçấo da Biodiversidade (ICMBio), e pelo conselho deliberativo, uma instância gestora da unidade constituída por órgãos públicos, sociedade civil e setor privado da região (Cunha \& Loureiro, 2009; Palmieri \& Veríssimo, 2009), caracterizando uma nova forma de arranjo institucional pautado na gestáo participativa, resultante da influência da sociedade civil nas questóes públicas, em especial após a Constituição Federal de 1988 (Jacobi, 2005).

As Resex têm se destacado pela aceitação e participação das populaçóes residentes (Ferreira, 2002) e representado avanços expressivos para a conservação da biodiversidade, em especial na zona costeira (Oliveira, 2012), contudo há descontentamento acerca do papel delas, como o desconhecimento dos atores do que de fato compreende uma Resex (Burda et al., 2007), os conflitos acerca dos processos de criação e mecanismos de gestão (Aguiar et al., 2011a), além de serem usadas, inclusive, como trampolins políticos (Figueiredo Filho \& Soares, 2010).

Acerca do conselho deliberativo, é a instância de gestáo participativa que favorece as negociaçóes e o exercício da democracia (Loureiro \& Cunha, 2008) e pode ser compreendida como instrumento da governança ambiental por enfatizar as formas de ingresso da base comunitária para a gestáo (Dearden et al., 2005; Kapaciauskaite, 2011). Considerada como novo paradigma em relaçáo à gestáo participativa e comunitária (Kothari, 2008), a governança contribui para a gestão de AP de forma participativa (Newig \& Fritsch, 2009; Hirschnitz-Garbers \& Stoll-Kleemann, 2011).

Pesquisas sobre processos participativos (Silva, 2007; Kalikoski et al., 2009; Fadigas \& Garcia, 2010; Soares et al., 2011) e governança em AP (Dearden et al., 2005; Duffy, 2006; Brondizio et al., 2009; Cudney-Bueno et al., 2009; Cantuária \& Ribeiro, 2012) vêm sendo objetos de estudo por contemplar aspectos relevantes para a efetividade da UC. Nesse sentido, visando contribuir com estudos na zona 
costeira e marinha, entende-se que a análise do conselho deliberativo em Resex e, consequentemente, a compreensão acerca dos elementos que compóem os processos decisórios, pode contribuir para o aprimoramento da gestáo da UC e subsidiar a definição de políticas públicas, inclusive em relação à gestão pesqueira.

Portanto, noâmbitodeuma Resex, esse trabalhocontempla as discussões do conselho deliberativo mediante identificação e análise dos principais elementos que influenciaram e/ ou influencia as decisóes relativas às atividades de pesca e a gestão da Resex, incluindo uma análise dos princípios da governança em AP. Adotou-se como área de estudo a Resex de Canavieiras, localizada na regiāo litorânea do sul do estado da Bahia, Brasil, constituída por ato federativo em 2006.

\section{ZONA COSTEIRA E MARINHA}

Evitar a degradação dos ecossistemas costeiros e marinhos, perda da biodiversidade, práticas insustentáveis de pesca e atividades que gerem danos ao meio ambiente foram os alertas mundiais da $10^{\mathrm{a}}$ Conferência das Partes dos Países Signatários (COP10) da Convenção sobre a Diversidade Biológica (CDB) ocorrida em Nagoya-Japão em 2010, desencadeando a "revisáo dos planos de trabalho da biodiversidade costeira e marinha e sobre áreas protegidas" (MMA, 2010: 28).

Em função dos países signatários não terem cumprido integralmente as metas para redução da biodiversidade entre 2002-2010 (SCDB, 2010), fez-se necessária a definição de um novo compromisso mundial - o Plano Estratégico para Diversidade Biológica 2011-2020, também conhecido como Metas de Aichi e composto por vinte metas, que servirá como norteador para o estabelecimento de novos programas e planos nacionais.

Considerando a importância da zona costeira e marinha, nesse Plano foram estabelecidas três metas internacionais que, na medida do possível, devem ser contempladas no delineamento de programas, planos e açóes de cada país signatário, a saber:

Meta 06: Até 2020 todos os estoques de peixes, invertebrados e plantas aquáticas devem ser geridos $e$ explorados legalmente, de maneira sustentável $e$ aplicando a abordagem ecossistêmica, de maneira a evitar a sobrepesca, com planos e medidas de recuperação em vigor para todas as espécies sobrepescadas, com a pesca praticada sem impactos adversos significativos sobre espécies ameaçadas e ecossistemas vulneráveis, e os impactos da pesca sobre os estoques, as espécies e os ecossistemas devem estar dentro dos limites de segurança ecológica;

Meta 10: Até 2015, as múltiplas pressóes antrópicas sobre os recifes de coral e outros ecossistemas vulneráveis afetados pelas alteraçóes climáticas ou pela acidificação dos oceanos devem ter sido minimizadas, de modo a manter sua integridade e funcionamento;

Meta 11: Até 2020, pelo menos 17\% das áreas terrestres $e$ de águas continentais e $10 \%$ das zonas costeiras e marinhas, principalmente as áreas de particular importância para a biodiversidade e para a manutençâo dos serviços ambientais, devem estar conservadas por meio de sistemas ecologicamente representativos e integrados dentro de paisagens terrestres e marinhas mais amplas, compostos por áreas protegidas ou outras medidas de conservação efetivas in situ, bem conectadas e geridas com eficácia e equidade (MMA, 2010:39).

Reconhece-se que o país ao longo das últimas décadas tem buscado estruturar seu ordenamento jurídico a fim de assegurar a conservação e uso sustentável dos seus recursos biológicos (MMA, 2010), o que se configura como fator determinante para alcance das metas assumidas, e em especial, destaca a condição atribuída ao meio ambiente, elevando-o a categoria de direito fundamental reconhecido pela Constituição Federal de 1988, em seu art'. 225 (Antunes, 2010), que incumbiu ao poder público assegurar, em uma primeira instância, a efetividade desse direito, impondo a obrigaçáo de definir, em todas as unidades da federação, espaços territoriais e seus componentes a serem especialmente protegidos $\left(\$ 1^{\circ}, \mathrm{III}\right)$, dentre os quais as UC's. A fim de regular esses espaços territoriais, instituiu-se o SNUC, que regulamentou as categorias de UC, em âmbito federal, estadual e municipal, e classificou-as em UC de Proteção Integral e UC de Uso Sustentável.

Visando o ordenamento da zona costeira, o país instituiu o Plano Nacional de Gerenciamento Costeiro (PNGC), mediante Lei $\mathrm{n}^{\circ} 7.661 / 1988$ (DOU, 1988), com objetivo de ordenar o uso dos recursos naturais e a ocupaçáo dos espaços litorâneos, com envolvimento das três esferas governamentais - federal, estadual e municipal - e a definição de instrumentos de gestão, sendo quatro gerenciais e cinco operacionais (Vianna et al., 2012). Segundo Polette \& Silva (2003), o PNGC significa um importante compromisso com o desenvolvimento sustentável da zona costeira, porém a sua implementação, desenvolvimento e gestão dependem, sobremaneira, do envolvimento da sociedade em todos os níveis, em especial, local. Os autores, em pesquisa no litoral centro-norte do estado de Santa Catarina, constataram que $78 \%$ dos atores entrevistados desconhecem o que significa o PNGC e que 22\%, não tinham certeza a respeito. Tal realidade serve de alerta para os governantes, visto que o êxito do gerenciamento costeiro pressupóe o envolvimento da sociedade nos processos decisórios, o que pode compreender processos de governança. Recentemente, Vianna \& Polette (2012), ao analisarem os instrumentos de gestão costeira e o Plano Local de Desenvolvimento da Maricultura, em Santa Catarina, constataram envolvimento e participação, embora setorial, da sociedade.

Atento ao que estabelece o Programa de Trabalho sobre Áreas Protegidas da CDB (Decisão VII/28 - 7a Conferência das Partes, 2004), o país aprovou o Plano Estratégico Nacional de Áreas Protegidas (PNAP), mediante Decreto $\mathrm{n}^{\circ}$ 5.758/2006 (DOU, 2006), e definiu princípios, diretrizes e açóes para o estabelecimento de um sistema abrangente de AP ecologicamente representativas, efetivamente manejadas, integradas às áreas terrestres e marinhas mais amplas, até 2015 (MMA, 2006).

Ao estabelecer o PNAP, açóes específicas para a zona costeira e marinha foram delineadas a fim de assegurar o estabelecimento de AP - instituição de UC - como forma de realizar a gestão da atividade pesqueira. Também 
estabeleceram as zonas vedadas à pesca ou reservas marinhas como ferramentas de gestão pesqueira, fornecendo um incentivo político para o estabelecimento de um sistema de AP marinhas, como um dos instrumentos mais eficientes para a recuperação de estoques pesqueiros. Tal medida decorreu, em grande parte, pela identificação das causas de ameaça à biodiversidade costeira, dentre as quais podem ser citados: o desenvolvimento costeiro, a poluição e as atividades pesqueiras, e para a biodiversidade marinha, as atividades pesqueiras (MMA, 2010).

De acordo com o CDB, o país tem registrado avanços em relação à conservação da biodiversidade, como proteção de habitats, monitoramento de impactos e redução das ameaças de desmatamento e fogo, porém poucos avanços foram obtidos acerca da recuperação de estoques pesqueiros, espécies exóticas, repartição de benefícios e acesso regulamentado a recursos genéticos (SCDB, 2010).

Atualmente, o Brasil destaca-se por ser a $4^{\mathrm{a}}$ maior superfície terrestre coberta por UC, sendo estas áreas importantes inclusive para a economia nacional pelos seus serviços ecossistêmicos (Medeiros et al., 2011). Entretanto, para os ecossistemas costeiros e marinhos, faz-se imperativo a urgência por açóes que possam conter o ritmo acelerado de descaracterização das paisagens litorâneas e a depleção dos estoques pesqueiros (MMA, 2010).

Outro fator preocupante refere-se à alta concentração populacional das regióes litorâneas. Sendo atualmente o $5^{\circ}$ país mais populoso do mundo, com o total de 190.755 .799 habitantes ${ }^{1}$, estima-se que um quarto da população brasileira reside na extensa faixa costeira, que abrange dezessete estados litorâneos, o que configura-se um importante indicador da pressão antrópica que afeta os recursos naturais, sob diferentes formas de desenvolvimento como turismo, infraestrutura urbana, carcinicultura e atividades portuárias (MMA, 2010).

Considerando a importância do estabelecimento e manutenção das UC na faixa litorânea, com adequado uso dos recursos manejados, ressalta-se a relevância das Resex como instrumentos de gestão pesqueira. Dados do Cadastro Nacional de Unidades de Conservação $\left(\mathrm{CNUC}^{2}\right)$, em junho de 2012, confirmaram a existência de 87 Resex em área continental, o equivalente a $1,6 \%$ de $1.460 .606 \mathrm{~km}^{2}$ $(17,5 \%)$ da área continental protegida, e dezessete Resex marinhas, sendo $0,1 \%$ de $54.589 \mathrm{~km}^{2}$ (1,54\%) da área marinha protegida.

\subsection{Reserva Extrativista e Conselho Deliberativo}

A concepção da Resex está diretamente vinculada ao movimento social ocorrido na Amazônia, principalmente por parte dos seringueiros do Acre, no início da década de 1970, e estendido ao longo dos vinte anos seguintes (Chamy,

1 - Censo 2010-Instituto Brasileiro de Geografia e Estatística. http://www.ibge.gov.br/home/presidencia/noticias/noticia visualiza.php?id_noticia $=1766$

2 - http://www.mma.gov.br/images/arquivos/areas_protegidas/ cnuc/tabela_ucs_\%20esferagestao_\%2012junho2012.pdf
2002). Esse movimento marcado pela "luta de terra e garantia de modo de vida e cultura autônomos" (Cunha \& Loureiro, 2009:2), colidiu com as políticas de ocupação e exploração madeireira da Amazônia e visava alertar as autoridades sobre as práticas predatórias do ambiente natural (Chamy, 2002) num momento em que se buscava equalizar uma política de reforma agrária conduzido pelo Instituto Nacional de Colonização e Reforma Agrária (INCRA).

Impasses entre extrativistas e governo em relação à política de reforma agrária conduzida pelo INCRA na década de 1980 possibilitaram à Concessão do Direito Real de Uso, com base no Decreto-Lei nº 271/1967 (DOU, 1967), sendo este um contrato administrativo pelo qual o poder público transfere a título de direito real o seu domínio a particular, com usufruto temporário e a título gratuito. Em 1985, ocorreu o $1^{\circ}$ Encontro Nacional dos Seringueiros em Brasília que buscava solucionar a questáo fundiária, garantindo a proteçáo da floresta contra o desmatamento, sendo considerado fato decisivo para a criação das Resex em momento futuro (Cunha \& Loureiro, 2009; 2012).

Posteriormente, com a morte do seringueiro Chico Mendes em 1988 e as fortes pressóes internacionais e nacionais em prol de maior proteção a floresta tropical (Silva, 2007), o país legitimou a criação das Resex considerando o movimento dos seringueiros e reivindicação pelas terras de extrativismo, a necessidade de uma política de reforma agrária, bem como a necessidade de revisão de políticas públicas para Amazônia e o fortalecimento do movimento ambientalista.

Inicialmente constituídas como projetos de assentamentos extrativistas (Cunha \& Loureiro, 2012) em 1990, as Resex foram criadas como UC da Natureza mediante Decreto no98.897/1990 (DOU, 1990), e definida como espaços territoriais destinados à exploração auto-sustentável e conservação dos recursos naturais renováveis, por população extrativista $\left(\right.$ Art. $\left.1^{\circ}\right)$, regulada por Contrato de Concessão Real de Uso (Art. $4^{\circ}$ ) em função de ser área de domínio público (Allegretti, 2002), cujo contrato deve ser assinado pela comunidade outorgada (Associação dos Moradores). Após dez anos de tramitação, as Resex foram incorporadas como UC, instituídas pelo SNUC, com mudanças em relação às estruturas de gestão e decisão (Cunha \& Loureiro, 2009).

Apesar de não haver a diferenciação para o SNUC, existem duas modalidades de Resex ${ }^{3}$ : Resex da Amazônia e Resex Marinha. O governo federal criou a primeira Resex - a Reserva Extrativista do Alto do Juruá, no Acre (Allegretti, 2002; Medeiros, 2006), com finalidade de atender as demandas e expectativas das populaçóes tradicionais que faziam uso dos recursos da biodiversidade. Em 1992, já fora dos limites da região norte, foi criada a primeira Resex Marinha por ser distinta quanto aos recursos manejados: a Resex Marinha de Pirajubaé, no Estado de Santa Catarina (Schenini, 2004) e em 1997, a primeira Resex de mar aberto, a Resex Marinha do Arraial do Cabo no estado do Rio de Janeiro (Silva, 2007).

A concepção das Resex é resultado de um processo histórico de reconfiguração de forças sociais que teve

3 - http://www.ibama.gov.br/resex/resex.htm 
início no estado do Acre, onde o Estado deve atuar como garantidor dos direitos. Ressalta-se que as mudanças advindas do campo político no país, onde o Estado-nação se inseriu no neoliberalismo, contribuíram para que o movimento da luta de classes na década de 1990 adentrasse na arena da legalidade e consolidasse a conquista de um direito - a criação da Resex (Cunha \& Loureiro, 2009). O caráter institucional e os novos arranjos institucionais constituidos em funçáo da Resex têm requerido uma maior preparação por parte dos extrativistas, visando uma atuação mais inclusiva. Esta mobilização social se realiza, principalmente, por meio da participação das comunidades tradicionais nos conselhos deliberativos, atuando ativamente na gestão.

Em relação aos conselhos, de acordo com o SNUC, as UCs podem ter conselhos consultivos ou participativos e devem ter representaçóes dos órgãos públicos, sociedade civil e setor privado, atuante na região, conforme definido no Decreto $\mathrm{n}^{\circ} 4.340 / 2000$ (DOU, 2000). O conselho deliberativo compartilha dos mesmos objetivos do conselho consultivo - garantir a transparência da gestáo da UC, contribuir para a elaboração e implantação do plano de manejo, integrar a UC às comunidades, setor privado, instituiçôes de pesquisa, organizações não governamentais, poder público, bem como as outras áreas de proteção situadas no entorno -, além de também absorver as funçóes de aprovar o plano de manejo e a contratação de Organização da Sociedade Civil de Interesse Público (OSCIP) para gestão compartilhada, o que nesse caso, em decorrência do maior poder decisório, faz-se necessidade um maior envolvimento e competência na função de conselheiro (Palmieri \& Veríssimo, 2009).

Jacobi (2003) alerta que embora os conselhos representem arranjos institucionais inovadores, visto que são gestores de políticas públicas, devem ter as capacidades necessárias para tornar suas ações também inovadoras. O SNUC estabelece que haja conselhos deliberativos para as Resex, Reservas de Desenvolvimento Sustentável (RDS) e Reserva da Biosfera (Palmieri \& Veríssimo, 2009). A fim de discipliná-los no que tange a formação e funcionamento do conselho para as Resex e RDS, o ICMBio definiu as diretrizes, normas e procedimentos (DOU, 2007).

Cunha \& Loureiro (2009) alertam que a forma com que o conselho é constituído é mais relevante do que meramente a sua existência. Afirmam que o conselho pode variar em relação ao grau de participação dos envolvidos, a depender de como é viabilizada a participação dos comunitários e que a gestão deve atentar para as razóes de sua existência visto que esta categoria de UC está alicerçada no saber das populações tradicionais ao lidar com seu território, sendo estes os protagonistas nas açôes de gestão, incluindo, a construção do conselho. Embora atuem como instâncias de participação e democracia, os conselhos, por si só, náo devem ser vistos como garantia destes, uma vez que dependerão da condução e dos interesses partilhados (Loureiro \& Cunha, 2008).

Ao avaliar o tema, em 2002, Chamy (2002:5) já sinalizava para o aumento do número de pedidos para a criaçáo de Resex como um "indício de fortalecimento e amadurecimento das estruturas de organização e mobilização social de uma parcela populacional marginalizada na defesa de seus direitos tradicionais". Atualmente, decorrido uma década, continua a demanda por novas Resex. Embora haja demanda por novas Resex, torna-se necessário atenção às responsabilidades assumidas pelas que já foram constituidas, como a elaboração e execução do plano de manejo e a definição e funcionamento do conselho deliberativo. Reconhece-se o esforço do Poder Público para regularizar as Resex, a exemplo, no ano de 2011 foram finalizados sete planos de manejo e vinte e quatro encontram-se em fase de elaboração, e sobre os conselhos deliberativos, foram constituídos oito (ICMBio, 2012).

\subsection{Governança em Áreas Protegidas}

A inserção da temática governança em documentos e convençôes internacionais, como União Internacional para Conservação da Natureza (IUCN), CDB e a Organização das Naçôes Unidas para a Educação, a Ciência e a Cultura (UNESCO), contribuíram para a difusão e divulgação do tema no que tange às AP (Graham et al., 2003; BorriniFeyerabend, 2004; Ivanova et al., 2007). Distinto do conceito de governo, a governança engloba as açóes do Estado e atores (Lemos \& Agrawal, 2006) e representa as interaçóes entre estruturas, processos e tradiçôes que determinam como o poder e as responsabilidades são exercidos, como as decisões são tomadas e como os cidadãos ou stakeholders se manifestam (Graham et al., 2003). Um importante aspecto da governança refere-se a participaçáo de atores não-estatais nos processos decisórios em diferentes níveis de governança (Duffy, 2006; Kluvánková-Oravská et al., 2009).

A governança em AP pode ser classificada em quatro tipos: a) AP governamentais; b) AP co-manejadas; c) AP privadas; e d) Áreas conservadas pela comunidade (BorriniFeyerabend, 2004). No caso da Resex, por ser uma área de domínio público, caracteriza-se como AP governamental, cuja autoridade, responsabilidade e responsabilização estáo sob a competência de agência em nível nacional, regional ou municipal, e a administração pode ser exercida diretamente ou delegada mas a posse e controle continua em poder do governo.

Kapaciauskaite (2011) afirma que conhecer sobre a governança ambiental é imprescindível para compreender sobre as relaçôes estabelecidas e, consequentemente, sobre os resultados obtidos em AP e acrescenta que, por conta da inserção de novos atores, caracterizando a governança horizontal. A autora acrescenta que a governança desafia o sistema de governo à medida que fornece novos recursos, transparência e divulgação ao tempo em que exige mais responsabilidade e participação. Newig \& Fritsch (2009), a partir da análise de governança multi-níveis, afirmam que a governança participativa deve viabilizar uma melhoria da qualidade das decisóes por incorporar o conhecimento local. Para os autores, a inclusão das partes interessadas facilita a aceitação das decisóes, permitindo o cumprimento e aplicação na base.

Graham et al. (2003), ao analisarem os Programas de Desenvolvimento das Naçóes Unidas em relação a governança, sugeriram cinco princípios da boa governança, a saber: 1) Legitimidade e Voz; 2) Direção; 3) Execução; 4) Responsabilidade; e 5) Justiça. Os autores enfatizam que os princípios podem contribuir para comparar as formas de governança e auxiliar na resolução de problemas e desafios, através de uma abordagem baseada em princípios com 
a identificação de lacunas ou pontos fracos em regime de governança para fins de melhorias. Contudo, alertam, que é possível que ocorram conflitos ou sobreposiçóes de princípios, visto que nenhum é absoluto em sua aplicação face as influências do contexto sociocultural, histórico e tecnológico.

Como subsídio a análise da atuação do conselho deliberativo em relação aos objetivos inerentes à Resex - AP com recursos manejados (categoria VI, IUCN) -, serão considerados os princípios da boa governança em $\mathrm{AP}$ propostos por Graham et al. (2003) e que vêm sendo objetos de estudos (Dudley, 2008; Rauschmayer et al., 2009).

\section{MATERIAL E MÉTODOS}

A abordagem deste estudo classifica-se como pesquisa exploratória de cunho qualitativo. No que se refere aos procedimentos metodológicos, foi realizada pesquisa documental e uso de dados secundários, com base em atas do conselho deliberativo da Resex de Canavieiras e das representaçóes deste conselho. De forma complementar à análise das discussões, as atas foram avaliadas com base nos princípios da boa governança (Graham et al., 2003).

Em relação à escolha da área de estudo, descrita a seguir, foram considerados os estudos de Aguiar et al. (2011a; 2011b). Optou-se por uma Resex cuja maior motivação para a criaçáo da Resex esteve centrada nas questôes socioeconômicas, em declínio à época, bem como na luta pela defesa do meio ambiente frente às propostas da iniciativa privada de construção de hotéis Resorts na localidade. Registra-se ainda a existência de posicionamentos antagônicos em relação aos seus benefícios e gestão.

No que tange ao tema escolhido, em pesquisas realizadas por Seixas \& Kalikoski (2009) sobre a produção científica e artigos de divulgação relacionados à gestáo participativa da pesca no Brasil, foram registrados um total de 97 documentos, entre artigos científicos, de divulgação, livros ou capítulos de livros, materiais para divulgação, projetos de pesquisa e/ou pesquisa-ação, relatórios técnicos, resumos de apresentaçóes em reuniốes científicas, teses/dissertaçóes/monografias e trabalhos/documentos técnicos, dos quais não se identificou nenhum estudo específico cujo objeto de análise fosse atas das decisóes do conselho deliberativo, especificamente, de Reservas Extrativistas. Este fato destaca a relevância da presente pesquisa, que pode oportunizar novos estudos nesta área, bem como subsidiar açôes do poder público no que se refere à gestão participativa pesqueira no Brasil.

Assim, sustenta-se a idéia de que a pesquisa atende aos fins aos quais se propóe, que é apresentar informaçóes, decisōes e propostas geradas no âmbito do conselho deliberativo da Resex cujo processo gestão participativa está em construção.

\section{1. Área de Estudo}

A Resex de Canavieiras (Figura 1), constituída por meio do Decreto $s / n^{\circ}$, de 05 de junho de 2006, está situada em zona costeira e em faixa terrestre do sul do estado da Bahia, compreendendo os municípios de Belmonte, Canavieiras e Una, totalizando $100.645,85$ ha, sendo 5.500 ha de terra firme, 15.500 ha de manguezais e rios e 79.000 ha de mar, e tem como objetivo proteger os meios de vida e a cultura da população extrativista residente na área de sua abrangência e assegurar o uso sustentável dos recursos naturais da unidade.

As comunidades que compóem a Resex de Canavieiras são Oiticica, Puxim do Sul, Puxim de Fora, Barra Velha, Canavieiras (sede municipal), Atalaia, Campinhos e Barranco Alto, perfazendo um total de 2.300 famílias e tendo como principais atividades a pesca, a coleta de mariscos e a agropecuária familiar. As representaçóes dessas comunidades fizeram parte das localidades amostradas na pesquisa.

Ressalta-se que a Resex está inserida no bioma costeiromarinho e da Mata Attântica, sendo está última classificada como hotspot de biodiversidade (Tabarelli et al., 2005) e desta forma, é considerada área prioritária para conservação. Além disso, a Resex está localizada no Corredor Central da Mata Atlântica (CCMA), e possuir uma parte da sua poligonal inserida na área de amortecimento e conectividade da Reserva da Biosfera da Mata Atlântica do estado da Bahia.

Em relação ao seu ordenamento jurídico, o conselho deliberativo da Resex de Canavieiras foi criado em 2009 com a finalidade de contribuir para implantação e implementação

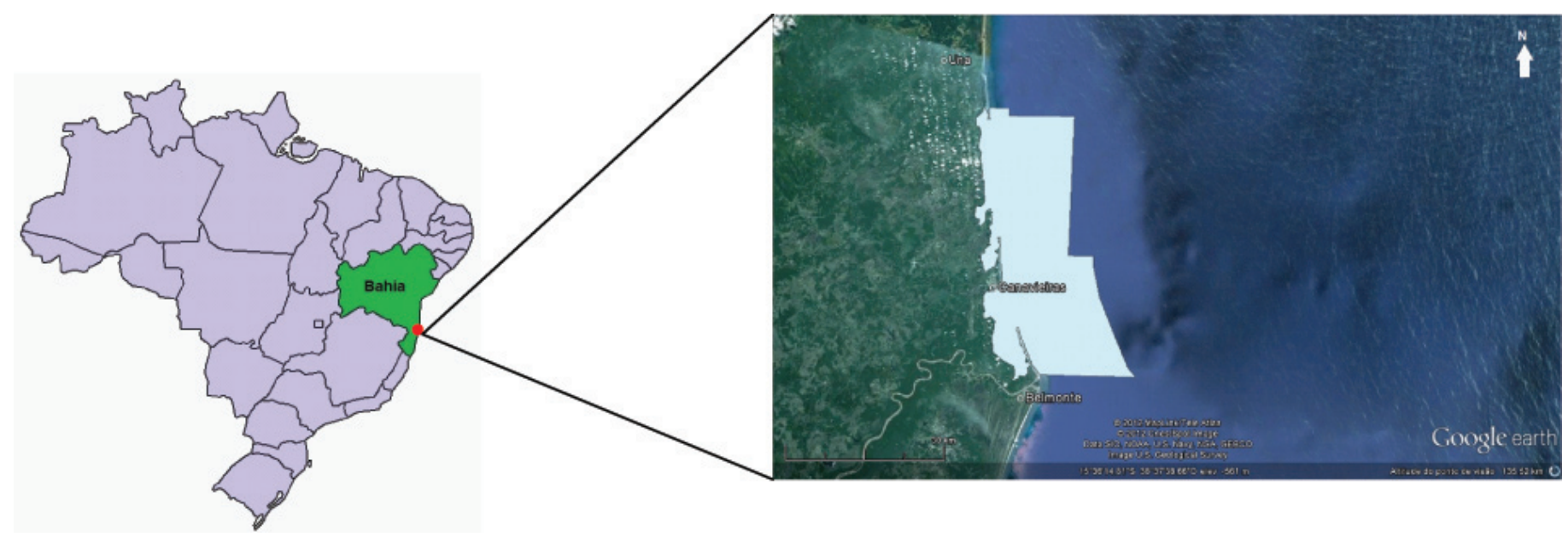

Figura 1. Localização da área de estudo.

Figure 1. Location of the study area. 
do plano de manejo e objetivos da respectiva Resex, e sendo composto por vinte e cinco representações (titulares e suplentes): órgãos federais, estaduais e municipais, instituição de ensino, associações, segmentos de artesão e agricultores familiares, colônias de pescadores, organizaçóes não-governamentais e, acerca do Termo de Concessão de Direito Real de Uso celebrado entre Ministério do Meio Ambiente e o ICMBio, em dezembro de 2010.

Registra-se transformaçóes socioeconômicas ocorridas a partir do final da década de 1980 em decorrência da crise na principal atividade - a cacauicultura, o que ocasionou uma migração rural-urbano com inversão da concentração populacional associada a redução da população municipal em aproximadamente 23\% (42.118 hab., em 1980 para 32.336 hab. em 2010). Atualmente, como fonte econômica, as principais atividades de Canavieiras se referem à agricultura - familiar e coco - pecuária e pesca marinha e estuarina. Em relação à pesca, registra-se que há um Acordo de $\mathrm{Pesca}^{4}$ que estabelece as normas para a gestão de uso sustentável dos recursos pesqueiros.

Estima-se que $80 \%$ dos pescadores praticam suas atividades nos manguezais e rios da Resex, sendo essas áreas as principais responsáveis pela sobrevivência dos extrativistas e, em área marinha, realizam atividades de pesca do camarão e peixes (Souza, 2011). Ressalta-se que Canavieiras está posicionada como importante produtor da espécie caranguejo-uçá (Ucides cordatus cordatus), um dos principais produtos da Resex (Aguiar et al.,2011b; Souza, 2011). Contudo, um dado alarmante coloca o município de Canavieiras em condição desfavorável: o município liderou o desmatamento na Bahia, 2010-2011, de acordo com dados recentes divulgados pela Atlas dos Remanescentes Florestais da Mata Atlântica 2008-2010, monitorados pela Fundação SOS Mata Atlântica e Instituto Nacional de Pesquisa Espaciais (SOS Mata Atlântica, 2012).

\subsection{Procedimentos metodológicos}

O estudo teve como objeto com finalidade de análise as informaçóes contidas nas atas do conselho deliberativo da Resex de Canavieiras e de suas representaçóes. Foram identificadas dezenove atas do período de 2009 a 2012, sendo onze atas do conselho deliberativo (numeradas: $1^{\circ}$ a $11^{\circ}$ ), e oito atas correspondentes as suas representaçóes.

No intuito de identificar as principais demandas registradas em ata, procedeu-se com a organização dos conteúdos, estruturando-os por ano, pauta, assuntos diversos, tipo de reuniáo (ordinária ou extraordinária), presidida por, anexos e números de participantes. Em seguinte, adotando a categorização dos temas-chave, procedeu-se com a identificação e análise dos assuntos abordados em reunião. No que se refere às discussôes relacionadas a atividades de pesca, buscou-se qualitativamente as informaçóes constantes nas atas. Além disso, os assuntos diversos tratados nas discussões foram depurados até a identificação de temaschave que serviram para registro da frequência da ocorrência destes.

4 - http://www.ibama.gov.br/ category/40?download=2592\%3A83-2006-.p

\section{RESULTADOS E DISCUSSÃO}

Foram identificadas um total de dezenove atas de reunióes ocorridas dos períodos de 2009 a 2012 sendo: uma ata em 2009, seis atas em 2010, uma ata em 2011, e onze atas em 2012. Para a análise, não houve distinção acerca do tipo de convocatória - caráter ordinário ou extraordinário.

Depreende-se da análise a falta de regularidade das reuniôes, o que pode ser devido, inclusive, à alta rotatividade do cargo de gestor do conselho deliberativo, presidido pelo ICMBio. Observou-se que não há uma rotina que permita inferir sobre a efetividade e a eficácia de algumas das decisóes tomadas no âmbito desse conselho. Nesse sentido, náo há nestes registros documentais quais as açóes tomadas e/ ou resultados, solicitaçóes e demais determinaçóes, o que não significa necessariamente que estas não tenham sido exitosas.

\subsection{Pesca}

Foi identificada a participação popular das comunidades nas decisóes relativas às atividades de pesca. Constatouse a presença da sociedade civil organizada, em diferentes representaçóes sociais da Resex.

No que tange as atividades da pesca, destacaram-se aspectos relevantes que podem ser considerados cruciais por ter ação direta sobre a atividade pesqueira na Resex. No ato de posse, ata $n^{\circ} 1$ de $12 / 11 / 09$, os conselheiros tomaram conhecimento, formalmente, do Acordo de Pesca da Resex de Canavieiras, o que caracterizava a preocupação com as atividades de pesca da área presentes desde a criação do conselho.

Contudo, apenas na ata $n^{\circ} 6$ de $10 / 11 / 10$ constatou-se a indicação de graves problemas relativos à pesca, gestão e infraestrutura na Resex. Foram apontados os seguintes problemas relacionados que afetavam direta ou indiretamente: a) presença de embarcaçóes de grande porte que vêm de fora (da Resex) para pescar camarão; b) pesca esportiva não controlada; c) pesca noturna por turistas com uso de lancha rápida durante o período de defeso; d) poluição da água por uso de moto aquática (jetski); e) catação de lambreta (atividade que destrói o manguezal provocando morte de caranguejos, aratus e siris); e f) catação de aratu predatória. Acerca das questóes comerciais, constatou-se a presença de atravessadores nas relaçóes de compra e venda de recursos pesqueiros e, no que tange a aspectos políticos, o município náo tem direito constitucional para tributar mariscos.

Ainda nesta ata, foram registradas medidas para sanar tais problemas como: i) realização de oficina para definir um plano de fiscalização e um plano de ecoturismo sustentável; ii) criação de grupo de trabalho para decisóes emergências (exemplo: proibir a catação de lambreta), mesmo antes da aprovação do plano de manejo; iii) proibição da pesca de lambreta com enxada.

A atuação dos agentes sociais de forma participativa, não apenas exigindo a atuação do poder público, mas se colocando como ente integrante dos processos decisórios da Resex, demonstrava a sua preocupação com espaços territoriais da Resex e com os recursos naturais, o que endossava o grau de maturidade dessas comunidades que vivenciaram um histórico de lutas e participação popular para concretização da Resex. 
Em seguida, na ata $\mathrm{n}^{\circ} 7$ de 29/09/11 foram apresentadas mais denúncias no que diz respeito às atividades pesqueiras como: a) pesca de mergulho no estuário de robalo e mero, sendo esta modalidade proibida no litoral, não no estuário; b) proibiçáo do uso de redinha, da pesca com enxada e pesca de aratu (que estavam ocorrendo à noite). Em relação as condiçóes ambientais, os conselheiros alertaram sobre a utilização da área da Resex como atrativo turístico para hotéis de luxo da região, pois suas embarcaçóes que alcançam altas velocidades poderiam destruir e assorear o rio, além de virar embarcações das comunidades. Repetidamente, os conselheiros enfatizaram a necessidade de maior fiscalização na Resex e registraram a importância da ação conjunta entre Marinha, ICMBio e comunidade. $\mathrm{Na}$ oportunidade, destacaram a necessidade do monitoramento pesqueiro (que foi realizado por empresa contratada pela Queiroz Galvão perfurações S.A.) para avaliar essa interação nos ambientes marinho e estuarino, o que não estava ocorrendo, bem como socializar os resultados com as representaçóes formais da Resex, no caso a Associação Mãe da Resex (AMEX).

Como sugestão aos problemas, foi sugerido o cadastramento dos extrativistas para que se tivesse controle do uso da área. Outros aspectos que mereceram destaque referiram-se a menção a uma lei municipal que impedia a captura de fêmeas e que um prefeito proibiu que o caranguejo saísse de Canavieiras sem antes abastecer o mercado interno. Tais aspectos vieram acompanhados de sugestóes, como o reforço a essa lei municipal que proibia a captura de fêmeas e a possibilidade de tributação na saída do caranguejo da cidade. Foi sugerido ainda que fossem estabelecidos limites de tamanho e velocidade para embarcações que trafegavam na área da Resex com o intuito de evitar prejuízos ao meio ambiente e as comunidades.

Constatou-se que houve participação e interesse dos atores em contribuir para a solução dos problemas locais, porém, representantes do conselho da Resex reconheceram que as medidas sugeridas dependeriam de maior envolvimento do poder público, incluindo poder local, além das organizaçôes e da sociedade civil.

Em registro na ata $\mathrm{n}^{\circ} 9$ de 16/07/12 vários problemas e ações foram destacados, tais como: a ausência de fiscalização por parte do ICMBio no período de defeso do robalo, o que levou pescadores de outras localidades a adentrarem na área da Resex; o IBAMA informou que no Estudo de Impacto Ambiental/Relatório de Impacto Ambiental da perfuração marinha do Bloco BM- J-I na Bacia do Jequitinhonha, referente a exploraçáo de petróleo no sul da Bahia, não foi contemplado os estudos da dinâmica da pesca e demais fatores associados, bem como a mobilidade dos pescadores, além disso, foi mais uma vez mencionado os impactos de lanchas grandes utilizadas por hotéis de luxo sobre o mangue. Como sugestão aos referidos problemas, foi indicada a complementação de dados de produção pesqueira e o envio destes questionamentos ao Ministério Público Federal. Além disso, como medida mitigadora, seria realizado monitoramento pesqueiro seis meses antes e após o início das atividades de perfuração. Foi sugerido também a definição de um conselho formado por representantes das comunidades para conceder as autorizaçóes diretas na Resex. Como sugestão de pauta da reunião seguinte foram indicados: a questão da barragem de Itapebi, a ampliação da Veracel em Belmonte e as embarcaçóes do Hotel Transamérica, o acordo de pesca e o plano de manejo, pesca de mergulho. Após essa reunião, as atas $n^{\circ} 10$ e $n^{\circ} 11$ destinaram-se a análise das autorizaçōes diretas, por meio de comissão constituí.

Dentre as discussóes relativas à pesca no âmbito do conselho deliberativo constatou-se que a fiscalização dos recursos naturais foi o assunto mais mencionado em reuniōes. Isso porque a comunidade receava pela perda desses recursos que asseguravam a sobrevivência de muitas destas comunidades. Assim, reforçava-se a idéia da fiscalização pelos atores, sendo co-responsáveis pela conservação dos recursos da Resex, ao tempo em que exigiam dos órgãos gestores e de fiscalização uma atuaçáo mais intensiva no monitoramento da UC.

Depreende-se da análise das atas a importância dos papéis assumidos pelos atores sociais durante as discussóes. Representantes das comunidades que compóem a Resex posicionavam-se para defender os direitos da coletividade, colocando-se como denunciantes de problemas que poderiam impactar as atividades de pesca (responsabilidade), e, nessa perspectiva, propondo aos órgãos gestores e fiscalizadores uma parceria para as ações de fiscalização (responsabilização).

Em relação às oito atas das representaçoos, em nenhuma foi explicitamente identificada discussōes acerca do tema gestão pesqueira.

\subsection{Gestáo}

A princípio, a discussão que se centrava na representatividade do conselho deliberativo, prioritariamente, em relação às atividades de pesca, expandiu-se para questóes mais amplas, abrangendo o próprio exercício da cidadania a partir da participação popular e do uso dos instrumentos de gestâo presentes na legislaçáo brasileira.

A partir da análise das atas das reunióes do conselho deliberativo foram identificados assuntos extensivos às atividades de pesca, como os instrumentos de gestão que reiteradamente surgiram nas pautas do conselho. Dentre os principais temas tratados relacionados aos instrumentos de gestáo da Resex, destacam-se: licenciamento ambiental, autorizaçóes diretas, plano de manejo, conselho deliberativo, fiscalização, controle de pesquisas; e Contrato de Concessão do Direito Real de Uso (CCDRU).

Cabe ressaltar que os referidos instrumentos de gestáo pautam-se na legislação ambiental vigente, em âmbito federal, conforme a Política Nacional de Meio Ambiente (Lei no 6.938/81), a Política Nacional da Reforma Agrária (especificamente a Norma de Execução no 93 de 19/07/2010, que dispóe sobre a aprovação de modelos de Contrato de Concessão do Direito Real de Uso (CCDRU) para os projetos de assentamento ambientalmente diferenciados: Projeto de Assentamento Agroextrativista, Projeto de Desenvolvimento Sustentável e Projeto de Assentamento Florestal) e do SNUC (Lei no 9.985/2000), conforme Quadro 01.

Dos instrumentos de gestão identificados após análise das atas, foi possível apontar a frequência de ocorrência de cada um dos temas-chave, sendo: conselho deliberativo (onze), sendo os assuntos abordados - eleiçóes, representaçóes, responsabilidades, e em casos específicos, a formação 
de comissão de análise e emissão de parecer referente à autorização direta do conselho da Resex; Licenciamento Ambiental (cinco), Autorizaçôes Diretas (quatro), CCDRU (quatro), Plano de Manejo (dois), e outros - capacitaçóes e pesquisas (dois). O tema-chave conselho deliberativo foi escolhido, tendo em vista $47 \%$ do total das atas avaliadas que tratavam de escolha de representantes do referido conselho, sendo este um tema recorrente. $\mathrm{Na}$ abordagem de Seixas \& Kalikoski (2009), é enfatizado que os diferentes tipos de arranjos institucionais - nomeados de várias formas e com sutis diferenças, retratam a preocupação acerca da necessidade do envolvimento dos pescadores na tomada de decisão. Nessa perspectiva, pode-se afirmar que o conselho deliberativo é um importante instrumento de análise, pois compóe o arranjo institucional para a gestão. Cabe destacar que a expressão gestão compartilhada para a pesca (Kalikoski et al., 2009) difere da conceituação definida no SNUC, que se refere a contratação de uma OSCIP mediante parceria para subsidiar a gestão da unidade (Palmieri \& Veríssimo, 2009). A importância desses temas-chave pode sinalizar a evolução das discussóes do conselho deliberativo para questôes mais abrangentes como a gestão participativa com base nos princípios de responsabilidade e responsabilização e o exercício da cidadania das representaçóes ligadas ao conselho da Resex.

\subsection{Governança}

Em relação aos princípios da boa governança implícitos nos processos da Resex, constatou-se que:

Princípio (1): Legitimidade e Voz - foi assegurado pelas condiçóes de criação e gestão da Resex, ratificando o caráter democrático exigível para UC desta natureza. A participação e envolvimento da populaçáo local representada pelos seus segmentos da sociedade se fizeram presente ao longo das reunióes ocorridas na Resex. Registra-se ainda que as referidas reunióes ocorreram em diferentes locais, atribuindo a relevância de cada comunidade para a composição da Resex. Constatou-se uma tendência a gestão colaborativa na tomada de decisóes, porém não se pode comprovar se de fato ela se faz presente na execução dos programas e ações. Em nenhuma ata foi constatado discriminação de gênero, raça, cor e religião. Não se pode afirmar se há grupos da sociedade civil e meios de comunicação independentes atuando como equilíbrio ao exercício dos poderes concedidos a gestores e políticos locais, visto que não foram citados em nenhum momento nas discussões da Resex, o que não implica que não existam.
Princípio (2): Direção - foi constatado esforços para a definição do plano de manejo, contudo de forma ainda pouco expressiva, embora ainda a Resex não dispóe deste instrumento. Contudo, foi expressa em ata a preocupação com a elaboração e discussão sobre o plano de manejo, compreendendo esta como determinante para a efetividade da UC. Através das atas pode-se concluir que há a presença de lideranças representativas dos extrativistas, exercidas principalmente pela AMEX. Ressalta-se, nesse quesito, a atuação do gestor da Resex (embora tenha ocorrida mudança de gestor no período) como líder na condução das discussóes registradas. Infere-se que tais discussóes são muitas vezes precedidas de discussões e negociações com lideranças locais, no exercício de sua funçáo de gestor. Em relação ao alinhamento às direçôes internacionais e legislação nacional, a gestão exercida por órgão federal - ICMBio - assegura esse Princípio.

Princípio (3): Execução - através da análise das atas, não é possível afirma que há eficiência na consecução dos objetivos da Resex, uma vez que requereria a análise de demais instrumentos de gestão, inerentes à avaliação. Contudo, pode se afirmar que existe capacidade para a realização das atividades por parte do órgão gestor e conselho deliberativo, item relevante para o exercício das atividades necessárias ao mandato. Constatou-se como exigência da comunidade a necessidade de ser informada acerca das pesquisas científicas, projetos e açôes em andamento na Resex, porém não foi constatado de forma sistemática, essa prestação de contas. Este Princípio envolve o monitoramento e avaliação das açóes realizadas, bem como gestão de riscos. É possível que tais açóes estejam contempladas no bojo do plano de manejo da Resex, em fase de elaboração, atribuindo inclusive as responsabilidades e responsabilização às partes, porém não foi identificado em registro de ata. Pode ser inferida desta análise que em função do tempo de constituição do conselho (em 2009) e demais prioridades somadas à substituição do gestor da UC, que ainda não foi possível uma sistematização para viabilizar o monitoramento e avaliação.

Princípio (4): Responsabilidade - foi percebido desde o início do conselho deliberativo, por parte do órgão gestor e do conselho deliberativo. Destaca-se que desde a primeira ata foi constatada a clareza na atribuição de responsabilidade e autoridade de agir, o que corrobora este princípio. Contudo, não foi registrada a amplitude dessa responsabilidade, o que se entende como prestaçáo de contas à sociedade como um todo, mediante transparência no acesso às informaçóes e

Tablea 1. Instrumentos de gestão identificados a partir da análise das atas - Resex de Canavieiras.

Table 1. Management tools identified from the analysis of the records - Resex of Canavieiras.

Política Nacional de Meio Ambiente

Política Nacional da Reforma Agrária

Licenciamento Ambiental

Autorizaçôes Diretas

Fiscalização
Sistema Nacional de Unidades de Conservação

Plano de Manejo

Conselho Deliberativo

Controle de Pesquisas

Fiscalização 
mecanismos de divulgação. Em relação às lideranças, sempre presentes e atuantes em reunióes, pode ser identificado a aceitação destes e as responsabilidades assumidas na condução de atividades.

Princípio (5): Justiça - depreende-se da análise que existe equidade na gestão da UC. Nenhuma informação conduziu a negação dessa prerrogativa, ao contrário, constatou-se a valorização dos saberes tradicionais, da participação dos conselheiros e demais presentes as reunióes do conselho deliberativo. Em nenhuma ata foi descrita qualquer ação discriminatória. Outro fator relevante refere-se ao gestor enfatizar acerca do ordenamento jurídico, a fim de que os atores tenham informações sobre a legislação vigente, bem como dos deveres e direitos da Resex. Contudo, não se pode afirmar que houve um aprendizado dessas informaçóes, ao passo que não foi identificada nenhuma forma de capacitação desses conselheiros, o que pode ser um indicativo importante para um processo de avaliação futura. Em relação a equidade na gestão da UC, depreende-se que todos os temas e problemas foram tratados de forma transparente.

\section{CONCLUSÓES}

Do ponto de vista da representatividade do conselho deliberativo para atividades ligadas a pesca é possível inferir que embora a participação dos atores ocorra, com uma atuação responsável e que, na medida do possível, buscase a responsabilização do atores, não há registros de que esta participação seja eficaz. Devido ao fato de náo haver resultados registrados das sugestóes, recomendaçôes e determinaçóes mencionadas nas atas - como, por exemplo, se houve aumento de fiscalização por parte dos agentes públicos ou se a fiscalização conjunta (Marinha, ICMBIo, IBAMA e comunidades) foi implementada - , não há como verificar ou mensurar os resultados obtidos a partir dessa sugestôes, recomendaçóes e demais decisões tomadas no âmbito do conselho. Este é o gap encontrado nesta pesquisa e que requereria uma pesquisa de campo para realizar as constatações necessárias à efetividade da gestão.

Concernente aos instrumentos de gestáo observa-se que estão sendo buscados e, na medida do possível, utilizados pelos atores das comunidades, a exemplo, acompanhamento de licenciamentos ambientais e autorizações diretas. Entretanto, torna-se difícil mensurar os resultados obtidos pela implementação destes instrumentos, uma vez que não há registros desses históricos em ata e em nenhuma forma de documentação.

Ressalta-se que processo de implementação do conselho deliberativo, dos instrumentos de gestão e da própria Resex são relativamente recentes e que esta modalidade de UC possui particularidades, quer seja pelo seu histórico, quer seja pela coletividade. Ainda não há regularidade nas reunióes do conselho e não existem registros documentais dos resultados das decisóes tomadas no âmbito do conselho e socializadas aos respectivos conselheiros. Entretanto, observa-se uma significativa evolução nas discussões, que tem se refletido no nível de responsabilidade dos atores e na responsabilização do demais agentes públicos envolvidos no processo de gestão desta UC. Ressalta-se ainda baixa frequencia do poder público local em reuniôes.
Em relação aos princípios da boa governança, percebe-se a predominância da Legitimidade e Voz e da Direção, em relação à Execução, Responsabilidade e Justiça, o que pode ser decorrente do grau de amadurecimento e envolvimento dos atores sociais ao processo de uma governança participativa. Importante destacar que a análise desses princípios podem contribuir para a resoluçáo de problemas e desafios, com a identificação de pontos fracos em regimes de governança para fins de melhorias, o que justificaria novos estudos nessa Resex.

Por fim, ressalta-se que pesquisas dessa natureza podem revelar os níveis de envolvimento dos atores sociais na gestão de AP, bem como, os princípios de governança presentes. Outro aspecto a ser destacado é a importância das discussóes no âmbito do conselho deliberativo de AP revelando que a riqueza dessas discussóes pode ir além da simples gestão pesqueira apenas para uso de tais recursos por essas comunidades, e sim, para a gestáo ambiental dos recursos naturais da UC como um todo.

\section{AGRADECIMENTOS}

Registramos nossos agradecimentos aos representantes e as comunidades da Reserva Extrativista de Canavieiras pelo acolhimento e oportunidade, à Universidade Estadual de Santa Cruz e ao Grupo de Pesquisa CAPES/Ciências do Mar, por oportunizar parcerias e convênios para implementação de projetos nesta UC.

\section{BIBLIOGRAFIA}

Aguiar, P.C.B.; Moreau, A.M.S.S.; Fontes, E.O. (2011a) Histórico de criação da Reserva Extrativista Marinha de Canavieiras (BA): posicionamentos antagônicos e gestão de território. Anais do VIII Encontro Baiano de Geografia I X Semana de Geografia da UESB (ISSN: 2179-4774), 14p., Vitória da Conquista, Bahia, Brasil. Disponível em http://www.uesb.br/eventos/ebg/anais/4e.pdf

Aguiar, P.C.B.; Moreau, A.M.S.S.; Fontes, E.O. (2011b) - Impactos na dinâmica ambiental do município de Canavieiras (BA) tendo a Resex como fator de influência. Revista GEOMAE - Geografia, Meio Ambiente e Ensino (ISSN: 2178-3306 ), 2(1):61-78, Campo Mourão, Paraná, Brasil. Disponível em http://www.fecilcam.br/ revista/index.php/geomae/article/viewFile/27/pdf_18

Allegretti, M.H. (2002) - A Construção Social de Politicas Ambientais - Chico Mendes e o Movimento dos Seringueiros. 827 p., Tese de Doutorado, Centro de Desenvolvimento Sustentável, Universidade de Brasília, Brasília, DF, Brasil. Não publicado.

Antunes, P. B. (2010) - Direito ambiental. 960p., Editora Lúmen Juris, Rio de Janeiro, RJ, Brasil. ISBN: 978-85375-0616-5.

Benjamin, A.H. (2001) - Introdução à lei do sistema nacional de unidades de conservação. In: A.H. Benjamin (coord.), Direito ambiental das áreas protegidas - $o$ regime juridico das unidades de conservação. pp.276-316, Forense Universitária, Rio de Janeiro, RJ, Brasil. ISBN: 8521802870

Borrini-Feyerabend, G. (2004) - Governance of Protected Areas, Participation and Equity. In.: Secretariat of the 
Convention on Biological Diversity. Biodiversity issues for consideration in the planning, establishment and management of protected area sites and networks. (ISBN: 92-807-2414-2), Technical Series 15 (i-vii):100-105, Montreal, Quebec, Canadá. Disponível em http://www. cbd.int/doc/publications/cbd-ts-15.pdf

Brondizio, E.S.; Ostrom, E.; Young, O.R. (2009) Connectivity and the Governance of Multilevel SocialEcological Systems: The Role of Social Capital. Annual Review of Environment and Resources, 34:253-78. doi: 10.1146/annurev.environ.020708.100707

Burda, C. L.; Polette, M.; Schiavetti, A. (2007) - Análise da Cadeia Causal para a Criação de Unidade de Conservação: Reserva Extrativista Marinha de Itacaré (BA) - Brasil. Revista de Gestão Costeira Integrada (ISSN: 1646-8872), 7 (1):57-67, Disponível em http://www.aprh.pt/rgci/ pdf/rgci7_7_Burdaetal.pdf

Cantuária, E.R.; Ribeiro, A.C. (2012) - Atores na Governança da APA do Rio Curiaú: relações nem tanto harmoniosas. Anais do VI Encontro da Anppas, 9p., Belém, PA, Brasil. Disponível em http://www.anppas.org.br/encontro6/ anais/ARQUIVOS/GT3-901-689-20120711072713.pdf

Chamy, P. (2002) - Reservas Extrativistas Marinhas: um estudo sobre posse tradicional e sustentabilidade. Anais do I Encontro da Associaçao Nacional de Pós-graduação e Pesquisa em Ambiente e Sociedade, 11p., Indaiatuba, SP, Brasil. Disponível em http://www.anppas.org.br/ encontro_anual/encontro1/gt/conhecimento_local/ Paula\%20Chamy.pdf

Cudney-Bueno, R.; Bourillón, L.; Sáenz-Arroyo, A.; Torre-Cosío, J.; Turk-Boyer, P.; Shaw, W.W. (2009) Governance and effects of marine reserves in the Gulf of California, Mexico. Ocean \& Coastal Management, 52 (3-4):207-218. doi:10.1016/j.ocecoaman.2008.12.005

Cunha, C.C.; Loureiro, C.F.B. (2009) - Reservas Extrativistas: Limites e contradiçóes de uma territorialidade Seringueira. Anais do XIX Encontro Nacional de Geografia Agrária, 25p., São Paulo,SP, Brasil. Disponível em http:// www.geografia.fflch.usp.br/inferior/laboratorios/agraria/ Anais\%20XIXENGA/artigos/Cunha_CC.pdf

Cunha, C.C.; Loureiro, C.F.B. (2012) - Estado educador: uma nova pedagogia da hegemonia nas reservas extrativistas. Revista katálysis, 15 (1):52-61. doi: 10.1590/ S1414-49802012000100005

Dearden, P.; Bennett, M.; Johnston, J. (2005) - Trends in Global Protected Area Governance, 19922002. Environmental Management, 36 (1):89-100. doi: $10.1007 / s 00267-004-0131-9$

DOU (1967) - Decreto-Lei $n^{\circ} 271$, de 28 de fevereiro de 1967 - Dispóe sobre loteamento urbano, responsabilidade do loteador, concessão de uso e espaço aéreo e dá outras providências. Diário Oficial da União - 28/02/1967, p.2460. Disponível em http://www.planalto.gov.br/ ccivil_03/decreto-lei/del0271.htm

DOU (1988) - Lei n ${ }^{\circ} 7.661$, de 16 de maio de 1988 - Institui o Plano Nacional de Gerenciamento Costeiro e dá outras providências. Diário Oficial da Uniáo - 18/05/1988, p.8633. Disponível em http://www.planalto.gov.br/ ccivil_03/leis/L7661.htm

DOU (1990) - Decreto $\mathrm{n}^{\circ} 98.897$, de 30 de janeiro de
1990 - Dispóe sobre as Reservas Extrativistas e dá outras providências. Diário Oficial da União - 31/01/1990 002122 2. Disponível em http://www.planalto.gov.br/ ccivil_03/decreto/Antigos/D98897.htm

DOU (2000) - Decreto n 4.340 , de 22 de agosto de 2002 - Regulamenta artigos da Lei $n^{\circ} 9.985$ de 18 de julho de 2000. Dispóe sobre o Sistema Nacional de Unidades de Conservação da Natureza-SNUC, e dá outras providências. Diário Oficial da União - 23/08/2002, p.9. Disponível em http://www.planalto.gov.br/ccivil_03/decreto/2002/ d4340.htm

DOU (2000a) - Lei $\mathrm{n}^{\circ}$ 9.985, de 18 de julho de 2000 - Regulamenta o art. 225, $₫ 1^{\circ}$, incisos I, II, III e VII da Constituição Federal. Institui o Sistema Nacional de Unidades de Conservação da Natureza e dá outras providências. Diário Oficial da União - Seção 1 19/07/2000, p.1. Disponível em http://www.planalto. gov.br/ccivil_03/leis/L9985.htm

DOU (2006) - Decreto n 5.758 , de 13 de abril de 2006 Institui o Plano Estratégico Nacional de Áreas Protegidas PNAP, seus princípios, diretrizes, objetivos e estratégias, e dá outras providências. Diário Oficial da Uniāo - 17/4/2006, p.1. Disponível em http://www.planalto.gov.br/ccivil_03/_ Ato2004-2006/2006/Decreto/D5758.htm

DOU (2007) - Instruçâo Normativa $n^{\circ} 02$, de 18 de setembro de 2007. Instituto Chico Mendes de Conservação da Biodiversidade - Disciplina as diretrizes, normas e procedimentos para formação e funcionamento do Conselho Deliberativo de Reserva Extrativista e de Reserva de Desenvolvimento Sustentável. Diário Oficial da União nº 182 - 20/09/2007 - Seção I, 102-104p. Disponível em http://www.icmbio.gov.br/portal/images/stories/o-quesomos/in022007.pdf

Duffy, R. (2006) - The potential and pitfalls of global environmental governance: The politics of transfrontier conservation areas in Southern Africa. Political Geography, 25(1):89-112. doi: 10.1016/j.polgeo.2005.08.001

Fadigas, A.B.M.; Garcia, L.G. (2010) - Uma análise do processo participativo para a conservaçáo do ambiente na criação da Reserva Extrativista Acaú-Goiana. Sociedade \& Natureza, 22 (3):561-576. Uberlândia, MG, Brasil. doi: $10.1590 / S 1982-45132010000300012$

Ferreira, L.S. (2002) - Políticas educacionais e desenvolvimento: a experiência da Reserva Extrativista Marinha do Souré, Pará. 105p., Dissertação de Mestrado. Universidade Federal do Pará, Belém, PA, Brasil. Não Publicado.

Figueiredo Filho, J.B.; Soares, N.L. (2010) - Reservas Extrativistas Marinhas e o II Plano Nacional de Reforma Agrária viram trampolins político no litoral do Pará. Anais do XVI Encontro Nacional dos Geógrafos (ISBN: 978-8599907-02-3), 7p., Porto Alegre, RS, Brasil. Disponível em http://www.agb.org.br/xvieng/anais/edp.php

Floeter, S.R; Ferreira, C.E.L.; Gasparini, J.L. (2007) - Os efeitos da Pesca e da Proteção através de UC's Marinhas: Três Estudos de caso e Implicações para os Grupos Funcionais de Peixes Recifais no Brasil. In.: Prates, A.P.; Blanc, D. (org.), Áreas aquáticas protegidas como instrumento de gestão pesqueira, pp.193-209, Ministério de Meio Ambiente, Secretaria de Biodiversidade e Floresta, Brasília, DF, Brasil. ISBN: 978-85-7738-077-0 
Disponível em http://www.em.ufop.br/ceamb/petamb/ cariboost_files/livro_areas_aquat.pdf

Graham, J.; Amos, B.; Plumptre, T. (2003) - Governance Principles for Protected Areas in the $21^{\text {st }}$ Century. Prepared for The Fifth World Parks Congress, Durban, South África. 50p., Institute On Governance, Ottawa, Ontário, Canadá. Disponível em http://iog.ca/sites/iog/files/ policybrief15_0.pdf

Hirschnitz-Garbers, M.; Stoll-Kleemann, S. (2011) Opportunities and barriers in the implementation of protected area management: a qualitative meta-analysis of case studies from European protected areas. The Geographical Journal, 177(4):321-334. doi: 10.1111/ j.1475-4959.2010.00391.x

ICMBio (2012) - Relatório de Gestâo do exercício de 2011. 203p., Instituto Chico Mendes de Conservação da Biodiversidade, MinistériodoMeioAmbiente, Brasília,DF, Brasil. In: http:/www.icmbio.gov.br/acessoainformacao/ images/stories/relatorios/rel_gestao_2011.pdf

Ivanova, M.; Gordon, D.; Roy, J. (2007) - Towards Institutional Symbiosis: Business and the United Nations in Environmental Governance. Review of European Community and International Environmental Law: RECIEL, 16(2):123-134. doi: 10.1111/j.14679388.2007.00558.x

Jacobi, P.R. (2003) - Espaços Públicos e práticas participativas na gestão do meio ambiental no Brasil. Sociedade e Estado, 18(1-2):315-338. doi: 10.1590/ S0102-69922003000100015

Jacobi, P. R. (2005) - Governança institucional de problemas ambientais. Politica \& Sociedade (ISSNe 2175-7984), 4(7):119-137, Florianópolis, SC, Brasil. Disponível em http://www.periodicos.ufsc.br/index.php/politica/ article/view/1969

Kapaciauskaite, I. (2011) - Environmental governance in the Baltic Sea Region and the role of non-governmental actors. Procedia Social and Behavioral Sciences, 14:90100. doi:10.1016/j.sbspro.2011.03.027

Kluvánková-Oravská, T.; Chobotová,V.; Banaszak, I.; Slavikova, L.; Trifunovova, S. (2009) - From Government to Governance for Biodiversity: The Perspective of Central and Eastern European Transition Countries. Environmental Policy and Governance, 19(3):186-196. doi: 10.1002/eet.508

Kothari, A. (2008) - Diversifying Protected Area Governance: Ecological, Social and Economic Benefits.In.: Secretariat of the Convention on Biological Diversity. Protected Areas in Today's World: Their Values and Benefits for the Welfare of the Planet. (ISBN: 92-9225-082-5), Technical Series 36(ivii):57-66, Montreal, Quebec, Canadá. Disponível em http://www.cbd.int/doc/publications/cbd-ts-36-en.pdf

Lemos, M.C.; Agrawal,A. (2006)-Environmental Governance. Annual Review of Environment and Resources, 31:297-325. doi: 10.1146/annurev.energy.31.042605.135621

Loureiro, C.F.B.; Cunha, C.C. (2008) - Educação ambiental e gestão participativa de unidades de conservação: elementos para se pensar a sustentabilidade democrática. Ambiente \& Sociedade, 11(2):237-253. doi: 10.1590/ S1414-753X2008000200003
Medeiros, R. (2006) - Evolução das tipologias e categorias de áreas protegidas no Brasil. Ambiente \& Sociedade, 9(1):41-64. Campinas, SP, Brasil. doi: 10.1590/S1414753X2006000100003.

Medeiros, R.; Young; C.E.F.; Pavese, H. B.; Araújo, F. F. S. (2011) - Contribuição das unidades de conservação brasileiras para a economia nacional: Sumário Executivo. 44p., UNEP-WCMC - United Nations Environment Programme - World Conservation Monitoring Centre, Brasilia, DF, Brasil. Disponível em http://www.pnuma. org.br/admin/publicacoes/texto/UCsBrasil_MMA_ WCMC.pdf

MMA (2006) - Plano Estratégico Nacional de Áreas Protegidas (PNAP). Decreto n ${ }^{\circ}$ 5.758, de 13 de abril de 2006. 44p., MMA-Ministério do Meio Ambiente, Secretaria de Biodiversidade e Florestas, Brasilia, DF, Brasil. Disponível em http://www.mma.gov.br/estruturas/240/_arquivos/ decreto_5758_2006_pnap_240.pdf

MMA (2010) - Panorama da conservação dos ecossistemas costeiros e marinhos no Brasil. 148p., MMA-Ministério do Meio Ambiente, Secretaria de Biodiversidade e Florestas, GerênciadeBiodiversidadeAquáticae Recursos Pesqueiros. Brasília, DF, Brasil. ISBN: 978-85-7738-142-5. Disponivel em http://www.mma.gov.br/estruturas/205/_ publicacao/205_publicacao27072011042233.pdf

Newig, J.; Fritsch, O. (2009) - Environmental Governance: Participatory, Multi-Level - and Effective? Environmental Policy and Governance, 19:197-214. doi: 10.1002/ eet.509

Oliveira, A.M.S. (2012) - Subsidios à Gestão da Reserva Extrativista Marinha de Soure-Marajó-Pará: uma análise dos problemas e conflitos socioambientais. 126p., Dissertação de Mestrado, Universidade Federal do Pará, Belém, PA, Brasil. Não Publicado.

Palmieri, R.; Veríssimo, A. (2009) - Conselhos de Unidades de Conservação: guia sobre sua criação e seu funcionamento. Imaflora: Piracicaba, São Paulo, SP; Imazon: Belém, PA, Brasil, 95p., ISBN: 978-85-98081-31-1. Disponível em http://www.imazon.org.br/publicacoes/livros/conselhosde-unidades-de-conservacao-guia-sobre

Perreira, P.F.; Scardua, R.P. (2008) - Espaços Territoriais Especialmente Protegidos: conceito e implicaçóes jurídicas. Ambiente \& Sociedade, 11(1):81-97, Campinas, SP, Brasil. doi: 10.1590/S1414-753X2008000100007

Polette, M.; Silva, L.P. (2003) - GESAMP, ICAM e PNGC - Análise comparativa entre as metodologias de gerenciamento costeiro integrado. Ciência e Cultura (ISSN: 0009-6725), 55(4):27-31, Sociedade Brasileira para o Progresso da Ciência, Campinas, SP, Brasil. Disponível em http://cienciaecultura.bvs.br/pdf/cic/ v55n4/a17v55n4.pdf

Rauschmayer, F.; Berghöfer, A.; Omann, I.; Zikos, D. (2009) - Examining Processes or/and Outcomes? Evaluation Concepts in European Governance of Natural Resources. Environmental Policy and Governance, 19(3):159-173. doi: 10.1002/eet.506

SCDB (2010) - Panorama da Biodiversidade Global 3. Leite, E.J.(trad.), 94 p., SCDB-Secretariado da Convenção sobre Diversidade Biológica. Ministério do Meio Ambiente, Secretaria de Biodiversidade e Florestas. Brasilia, DF, 
Brasil. ISBN: 978-85-7738-118-0 Disponível em www. cbd.int/doc/publications/gbo/gbo3-final-pt.pdf

Schenini, P.C.; Costa, A.M.; Casarin, V.W. (2004) Unidades de Conservação: Aspectos Históricos e sua Evolução. Anais do Congresso Brasileiro de Cadastro Técnico Multifinalitário, 7p., Florianópolis, SC, Brasil. Disponível em http://www.ambiente.sp.gov.br/wp-content/uploads/ cea/PedroCarlosS.pdf

Seixas, C.S.; Kalikoski, D.C. (2009) - Gestão participativa da pescanoBrasil:levantamentodasiniciativasedocumentação dos processos. Desenvolvimento e Meio Ambiente (ISSN: 1518-952X), 20:119-139, Paraná, Brasil. http:// repositorio.furg.br:8080/jspui/bitstream/1/1359/1/ Gest $\%$ c3\%a3o\%20participativa $\% 20$ da\%20pesca $\% 20$ no $\% 20$ Brasil $\% 20$ proposta $\% 2 c \% 20$ projetos $\% 20 \mathrm{e} \% 20$ documenta\%c3\%a7\% 3\%a3o\%20de\%20processos.pdf

Seixas, C.S.; Kalikoski, D.C.; Almudi, T.; Batista, V.S.; Costa, A.L.; Diogo, H.L.; Ferreira, B.P.; Futemma, C.R.T; Moura, R.L.; Ruffino, M.L.; Salles, R.; Thé, A.P.G. (2011) - Gestão compartilhada do uso de recursos pesqueiros no Brasil: elementos para um programa nacional. Ambiente \& Sociedade, 14(1):23-44, Campinas, SP, Brasil. doi: 10.1590/S1414-753X2011000100003.

Silva, P.P. (2007) - Da Propriedade Coletiva ao CoGerenciamento: Liçóes da Primeira Reserva Extrativista Marinha Brasileira. In: Prates, A.P.; Blanc, D. (org.), Áreas aquáticas protegidas como instrumento de gestão pesqueira, pp.159-177, Brasília: MMA/SBF. ISBN: 978-85-7738077-0. Disponível em http://www.em.ufop.br/ceamb/ petamb/cariboost_files/livro_areas_aquat.pdf

Soares, M.O.; Paiva, C.C.; Freitas, J.E.P.; Lotufo, T.M.C. (2011). Gestão de unidades de conservação marinhas: o caso do Parque Estadual Marinho da Pedra da Risca do Meio, NE - Brasil. Revista de Gestão Costeira Integrada / Journal of Integrated Coastal Zone Management, 11 (2):257-268. doi: $10.5894 /$ rgci261

SOS Mata Atlântica. (2012) - SOS Mata Atlântica e INPE divulgam dados do Atlas dos Remanescentes Florestais da Mata Atlântica, no periodo de 2010 a 2011. São Paulo, SP, Brasil. Disponível em http://www.sosma.org.br/5697/ sos-mata-atlantica-e-inpe-divulgam-dados-do-atlas-dosremanescentes-florestais-da-mata-atlantica-no-periodode-2010-a-2011/

Souza, B.B.G. (2011) - Levantamento participativo de bens e serviços ambientais para estudos de valoração em reservas extrativistas em áreas de manguezais. Anais do IX Encontro Nacional da Ecoeco, 19p., Brasília, DF, Brasil. Disponível em http://www.ecoeco.org.br/conteudo/publicacoes/ encontros/ix_en/GT1-240-107-20110616160313.pdf

Tabarelli, M.; Pinto, L.P.; Silva, J.M.C.; Hirota, M.M.; Bedê, L.C. (2005) - Desafios e oportunidades para a conservação da biodiversidade na Mata Atlântica brasileira. Megadiversidade, 1(1):132-138, Conservação Internacional, Belo Horizonte, MG, Brasil, Disponivel em http:/www.conservacao.org/ publicacoes/files/Megadiversidade_abrolhos.pdf

Vianna, L.F.N.; Bonetti, J.; Polette, M. (2012) - Gestão costeira integrada: análise da compatibilidade entre os instrumentos de uma política pública para o desenvolvimento da maricultura e um plano de gerenciamento costeiro no Brasil. Revista de Gestão Costeira Integrada, 12(3):357-372. doi:10.5894/rgci335 